\title{
Reducing poverty in the first 18 years of life: monetary and multidimensional child poverty in Vietnam
}

\section{Keetie Roelen, Institute of Development Studies (IDS), UK Research brief}

This research brief presents findings from a mixed methods research project on monetary and multidimensional child poverty in Vietnam. It uses data from the Vietnam Household Living Standards Surveys 2004, 2006, 2008 and purposively collected qualitative data from 78 children and 145 adults in Mekong River Delta Region to understand patterns and drivers of monetary and multidimensional child poverty. In particular it aims to understand why some children may be multidimensionally poor despite living in a household that is not monetary poor and vice versa.

\section{Key messages}

- Income plays an important role in securing children's basic and physical needs and can also contribute to meeting psychosocial needs by alleviating stress and reducing peer inequality.

- Although strongly linked, household income is not considered a sufficient condition for addressing multidimensional child poverty. Monetary and multidimensional child poverty are different phenomena; children experiencing monetary poverty do not necessarily experience multidimensional poverty and vice versa.

- Evidence for the mismatch between monetary and multidimensional poverty is underpinned by findings from both quantitative and qualitative data, refuting the suggestion that it is attributable to measurement error.

- Mismatch between outcomes persists over time, and findings do not support the hypothesis that improvements in multidimensional child poverty lag behind improvements in monetary child poverty.

- Psychosocial factors including children's and particularly parents' awareness and attitudes play an important role in shaping multidimensional poverty outcomes despite children being monetary poor.

- Government policies and community support structures can play an important role in mitigating the effect of monetary poverty by providing support to secure children's basic needs, particularly education and housing, despite low income or wealth. Access to official documentation is crucial in gaining access to services.

\section{Monetary and multidimensional child poverty in Vietnam}

Children and adults were asked to describe what constitutes good child wellbeing (or lack of multidimensional child poverty) and household wealth (or lack of monetary poverty) and to assess their own situations with respect to these elements. Important elements of multidimensional child poverty include basic and physical needs such as education, nutrition and shelter, a positive balance in use of time on going to school, study, leisure and working for the family, psychosocial elements such as good relationships within the households and the receipt of love and affection from caregivers. Important components of monetary poverty include the lack of sufficient income or the means for earning such an income, such as being healthy and able-bodied, having a stable job and having land. Issues such as living in poor housing or having a job far away from home are also considered to denote poor wealth.

Vietnam has seen great improvements in its poverty situation in the last two decades. Monetary poverty has steadily decreased since the Doi Moi reforms in the mid-1990s with the national poverty rate having been reduced from 58\% in 1993 to 15\% in 2010 (WB 2012). The incidence of multidimensional poverty (based on the Multidimensional Poverty Index (MPI) methodology) was 4.2\% in 2011 (OPHI 2015). These positive trends also hold for child poverty, as indicated in Figure 1. Analysis of indicators underlying the multidimensional poverty measure indicates that most rapid improvements occurred in the areas of shelter, water and sanitation (Roelen 2015). A comparison between overall poverty figures and child-specific estimates highlights that children are in a disadvantaged position, however, particularly with respect to multidimensional poverty. 
Figure 1 Monetary and multidimensional child poverty rates

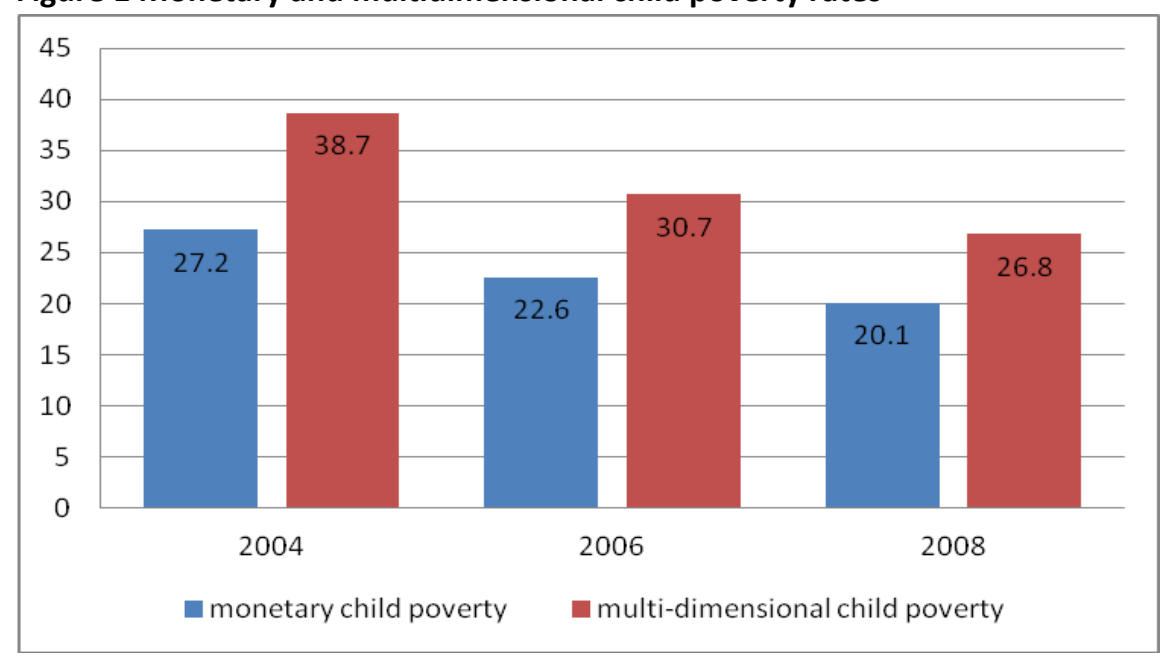

Source: Author's own calculations from VHLSS 2004, 2006 and 2008

Given the positive trends for both monetary and multidimensional child poverty, it is not surprising to find that having enough household income is indeed important in securing a good level of wellbeing for children, as indicated by adults and children in the qualitative data.

"Children in rich families get full enjoyment such as transporting, eating and drinking, clothing and better daily activities than the poor. They have balanced diets without fasting, thirst or craving, whereas the poor cannot afford those." [male adult, My Hao, Dong Thap]

"Rich children have a lot of nutritious food; they have 3 meals per day with fish, pork and chicken. Rich children do not need to earn money to assist parents. Poor children have to catch fish to assist parents." [boy, Long Hau, Dong Thap]

Analysis of the correlation between household expenditures and indicators underlying multidimensional child poverty corroborate these qualitative findings with significant correlation across all indicators (see Table 1). The sign for all indicators apart from 'having household head unable to work' is negative, reflecting that more household monetary resources is associated with lower deprivation in all but one area of multidimensional child poverty.

Table 1 Correlation between real per capita expenditure and child poverty indicators 2004, 2006 and 2008

\begin{tabular}{|c|c|c|c|}
\hline & 2004 & 2006 & 2008 \\
\hline & VHLSS, $n=12154$ & VHLSS, $n=10696$ & VHLSS, $n=9960$ \\
\hline & \multicolumn{3}{|c|}{ correlation with real per capita expenditure } \\
\hline multidimensional poverty status & $-0.334 * * *$ & $-0.299 * * *$ & $-0.281 * * *$ \\
\hline \multicolumn{4}{|l|}{ Indicators (age of child in years) } \\
\hline net enrolment (5-15) & $-0.149 * * *$ & $-0.151 * * *$ & $-0.159 * * *$ \\
\hline primary completion rate (12-15) & $-0.185^{* * *}$ & $-0.172 * * *$ & $-0.159 * * *$ \\
\hline visit to health facility (2-4) & $-0.132 * * *$ & $-0.148 * * *$ & $-0.123^{* * *}$ \\
\hline living in house with electricity $(0-15)$ & $-0.206 * * *$ & $-0.184 * * *$ & $-0.170 * * *$ \\
\hline living in proper house (0-15) & $-0.243 * * *$ & $-0.200 * * *$ & $-0.173^{* * *}$ \\
\hline living in dwelling with improved toilet (0-15) & $-0.432 * * *$ & $-0.405^{* * *}$ & $-0.384 * * *$ \\
\hline drinking from improved water source $(0-15)$ & $-0.189 * * *$ & $-0.191 * * *$ & $-0.198 * * *$ \\
\hline child work (6-15) & $-0.153^{* * *}$ & $-0.131 * * *$ & $-0.144 * * *$ \\
\hline having household head unable to work (0-15) & $0.038 * * *$ & $0.038 * * *$ & $0.072 * * *$ \\
\hline
\end{tabular}

Note: Asterisks refer to significance levels of coefficients: ${ }^{*}=p<0.1 ;{ }^{* *} p<0.05 ;{ }^{* * *} p<0.01$

Source: Author's own calculations from VHLSS 2004, 2006 and 2008 
Comparing correlation coefficients across years, the degree of correlation appears to decrease over time as both monetary and multidimensional poverty rates fall, contradicting the common notion that those who are hardest to reach in terms of poverty reduction efforts face multiple vulnerabilities but suggesting that children are affected by poverty in different ways.

\section{Case study I}

Long is a 16-year old boy who lives with his parents in Long Hau commune in Dong Thap province. He has three older siblings but they no longer live with the family. Long moved to this commune three years ago after the government prohibited the raking of fish - their main livelihood - in the area that they lived in. He has not been able to go to school since as his family needed all their money for building a new house. He drew his ideal house - one that has a mandarin garden and fish pond. His parents do not have stable jobs and struggle to earn enough money; Long's father works as a stone grinder and his mother sells lottery tickets. He only sees his parents late at night after they come from work. Long would like to work himself but he says he is too young to do so and has to stay at home. He spends most of his time doing domestic chores and looking after their chickens. He feels that his family is poorer

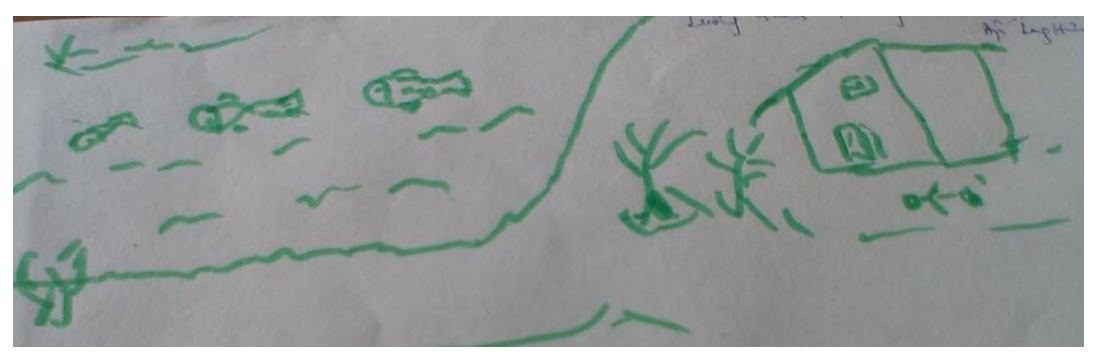
than other families because his parents don't have stable jobs and have no land. In terms of his own wellbeing, he indicates that is not good as he is not going to school, has to wear old clothes and can't eat nice foods, but he also indicates that there are other children in the community that are worse off than he is.

\section{Overlap and mismatch patterns}

Findings regarding the strong but decreasing correlation between indicators of monetary and multidimensional child poverty suggest that poverty is not concentrated within a single group of children. Indeed, a consideration of groups of children belonging to both, one or none of the poverty groups using Venn diagrams suggests that there is considerable mismatch as children living in multidimensional poverty are not necessarily monetary poor and vice versa (see Figure 2).

Figure 2 Child poverty groups in 2004, 2006 and 2008

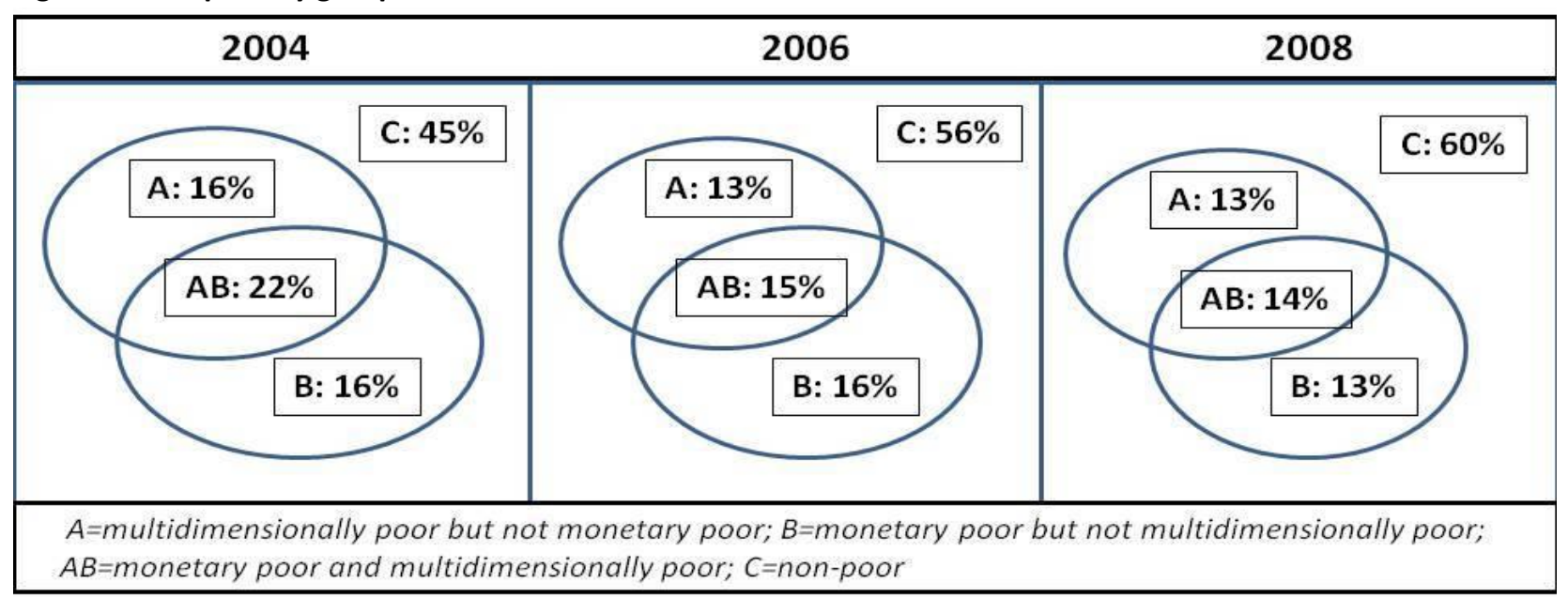

The mismatch between monetary and multidimensional poverty was also emphasised by both adults and children in the qualitative data, in terms of securing material and physical needs as well as psychosocial wellbeing. The level of monetary resources was not always considered a determinant for outcomes in elements of multidimensional poverty such as education.

"The rich as well as the poor have the same education level. It cannot say that the poor are not good in school. I have a friend who is a studious pupil although he is a poor child. At the end this school year, he passed the first level." [boy, Long Hau, Dong Thap] 
"We need to take care of them, money for spending isn't enough. We need to teach them to understand rights and wrongs so that they can distinguish. Then they will live better lives as well as have good base and ideas to become good people later." [male adult, My Hao, Dong Thap]

Patterns of mismatch when using different poverty measures are not limited to single time periods but persist over time (see Table 2). Roughly half of those children that are both monetary and multidimensional poor in one period remain in this situation in the next period. Transitions out of poverty are most frequent among those being only multidimensionally poor rather than those being exclusively monetary poor, particularly from 2004 to 2006.

Table 2 Transition matrices poverty groups in 2004, 2006 and 2008

\begin{tabular}{|c|c|c|c|c|c|c|c|}
\hline & & & 2006 & & & & \\
\hline & & $N$ & $A B$ & $A$ & $B$ & C & Total \\
\hline \multirow[t]{6}{*}{2004} & $A B$ & 567 & 49.6 & 14.5 & 26.1 & 9.9 & 100 \\
\hline & $A$ & 393 & 3.6 & 30.5 & 2.8 & 63.1 & 100 \\
\hline & $B$ & 407 & 13.8 & 8.9 & 39.3 & 38.1 & 100 \\
\hline & $C$ & 1126 & 0.1 & 5.9 & 3.5 & 90.6 & 100 \\
\hline & & & 2008 & & & & \\
\hline & & $\mathrm{N}$ & $A B$ & A & B & C & Total \\
\hline \multirow[t]{4}{*}{2006} & $A B$ & 352 & 53.4 & 10.8 & 26.7 & 9.1 & 100 \\
\hline & $A$ & 304 & 13.8 & 41.5 & 2.6 & 42.1 & 100 \\
\hline & B & 358 & 18.4 & 7.0 & 35.5 & 39.1 & 100 \\
\hline & C & 1479 & 1.4 & 5.9 & 4.3 & 88.4 & 100 \\
\hline
\end{tabular}

\section{Explaining child poverty mismatch}

Expanding research on differential outcomes for monetary and multidimensional (child) poverty suggests that explanations for mismatch between child poverty outcomes can be sought in a number of areas, including (i) measurement error, (ii) reductions in multidimensional poverty lagging behind reductions in monetary poverty and (iii) factors at the community, household and individual level.

We find little evidence that the mismatch between child poverty outcomes is attributable to measurement error. Analysis of multidimensional child poverty across the income quintiles reveals that although proportions of multidimensionally poor children decrease as income increases, one in 12 children in the highest income quintile

Figure 3 Community criteria for household wealth and child wellbeing

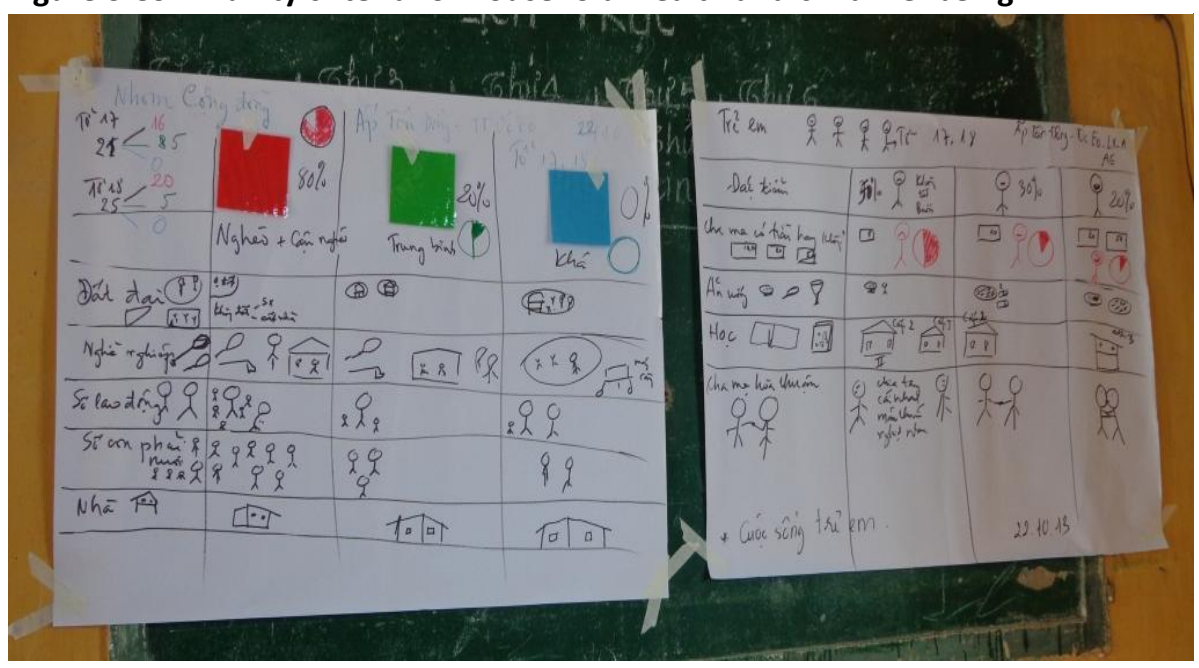

also experience multidimensional poverty. Findings from community exercises in four sites confirm that multidimensional and monetary poverty are conceptually and empirically different. Firstly, community members identified household wealth and material child wellbeing to be distinct concepts with distinct criteria (see Figure 3); criteria for household wealth and material child wellbeing as defined by community members overlap strongly with indicators that are used in the quantitative analysis, including income and employment to denote household wealth and education, sanitation and shelter for child wellbeing. Secondly, community members in all four sites identified households with inconsistent situation situations regarding monetary poverty and child wellbeing, confirming the empirical occurrence of poverty mismatch. 
The existence of lagged effects - i.e. the notion that improvements in multidimensional poverty lag behind improvements in monetary poverty - appears limited. If there were such a lagged effect, we would expect to see large proportions of children having moved from being simultaneously monetary and multidimensionally poor to being exclusively multidimensionally poor to being non-poor over time. Analysis of poverty transitions (see Table 2), however, indicates that children being simultaneously poor are more likely to be exclusively monetary poor rather than solely multidimensionally poor in the next period. Similarly, regression estimates reveal that being simultaneously poor in preceding periods increases a child's chance for belonging to any poverty group and not particularly for becoming exclusively monetary poor before moving out of poverty.

Household-level factors play a large role in explaining child poverty outcomes. Regression estimates point indicate that living with a household head that completed primary education or higher, is married, and is of Kinh/Chinese majority reduces a child's chances to belong to any poverty group. Living with an unemployed household head increases a child's chance to being monetary and multidimensionally poor or being exclusively multidimensionally poor, while living with a household head who is a skilled professional is associated reduces the chance to belong to those poverty groups. Qualitative findings pointed towards the importance of stable jobs and being able-bodied.

"Household poverty means that we do not have stable job, which results in unstable income. Health is also a factor which makes us wealthier or poorer. If we are strong, we can work and earn money."

[female adult, Long Hau, Dong Thap]

Most significant effects were found for children living in Mekong River Delta; children living in this region are considerably less likely to be exclusively monetary poor but face a higher chance to be exclusively multidimensionally poor or to experience monetary and multidimensionally poor simultaneously.

Perspectives from adults and children indicate that awareness and attitudes of both parents and children are important in determining good wellbeing for children even when the household has few monetary resources; in other words, psychosocial factors confound material factors when explaining differential child poverty outcomes. Findings also point towards the difficult reality of parents having to work long hours, sometimes leaving children in the care of others, to earn enough income and the adverse effect on child wellbeing.

"We are poor but we try to let our children study properly because we do not want our children to feel disadvantaged compared to other children." [female adult, Long Hau, Dong Thap]

"I think it is dependent on awareness, not dependent on either richness or poverty." [girl, My Hao, Dong Thap]

"My parents go to work far; I don't have enough money so I am off school for my two sisters studying."

[child, Oc Eo, An Giang]

Results with respect to community-level factors are mixed but do point towards the important role of government policies in mitigating the impact of monetary poverty or undermining child wellbeing in households with ample monetary resources. Regression estimates do not point towards a significant role for public services and infrastructure in influencing poverty status. Qualitative findings, however, do strongly indicate that government programmes play a positive role in securing children's needs despite household poverty, such as the 'poverty certificate' or 'poverty book' policy - particularly in relation to reducing tuition fees, health insurance and commune support (see Case study II). At the same time, experiences with government involvement were not altogether positive with a number of respondents suggesting that they were in poverty due to having been moved from the area that securing their main livelihoods (see Case study I). Respondents also pointed to the importance of having legal documentation in accessing services, regardless of income status.

[What is problem for children in this community?] "Having no educational material and no money for school fees, but the school and commune provide support to poor children" [child, Long Hau, Dong Thap] 
"Someone who is not exempted has to pay over 500,000 VND and other petty cash for schooling. Therefore, if people do not have the 'poverty book', they do not have enough money [to send their children to school]."

[girl, My Hoa, Dong Thap]

"My family is in poverty. The hamlet's officers have had us moved here and now we are in a difficult condition and there is no foundation to work anymore." [female adult, My Hoa, Dong Thap]

"I have never gone to school because my family lives in a rental house that means we are temporary residents, so I cannot have legal documents, like birth certificate for school application." [child, My Hao, An Giang]

\section{Case study II}

May is a 41-year old mother living in Long Hau commune in Dong Thap province with her husband and two sons. She is a daily labourer depending on seasonal activities such as picking mushrooms and cutting grass. Her husband is a construction worker but is less able to work since breaking his leg in 2003. The accident had a large impact on household wealth - as is clearly reflected in her family history diagram - and although things improved when her

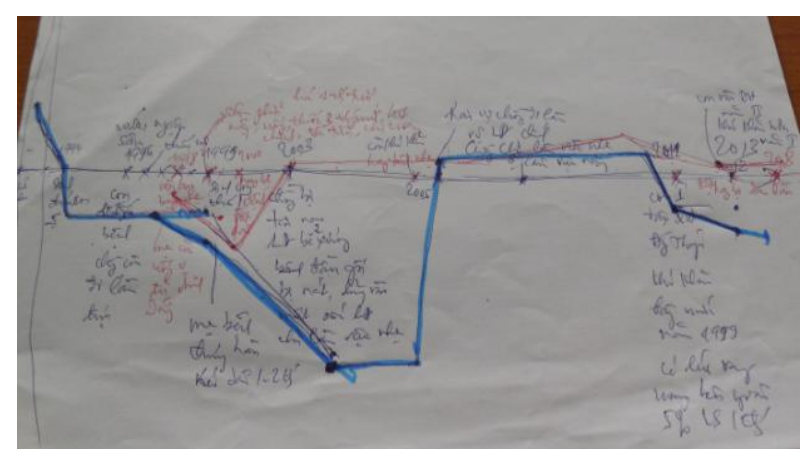
husband was able to work again, they did not reach the same
level of wealth as previously. Government programmes help in
ensuring that lower wealth does not undermine her children's
wellbeing: Her eldest son is currently attending university as
May was able to borrow money through a government scheme
to cover one-third of the tuition fees; she borrows from other
people to fund the rest. Her family also received the 'poverty
certificate' from the local authorities, securing their health
insurance and lower tuition fees for her youngest son.

\section{Policy implications}

- Child poverty requires comprehensive measurement, including measures of monetary and multidimensional poverty as well as information based on quantitative and qualitative data.

- Increasing incomes and particularly ensuring stable income flows are crucial in reducing both monetary and multidimensional child poverty.

- Strengthening education, awareness and aspirations among parents and children is important for reducing any type of poverty and can prevent multidimensional child poverty despite lack of monetary resources.

- Government policies such as social protection and social service provision are important mechanisms for reducing multidimensional child poverty despite living in monetary poverty. Securing access to legal documentation is crucial for ensuring children's access to services regardless of monetary poverty status.

\section{Further reading}

OPHI (2015) Viet Nam Country Briefing, Multidimensional Poverty Index Data Bank. Oxford: University of Oxford.

Roelen, K. (2015) Poor children in rich households and vice versa: A Blurred Picture, Lagged Effects or Hidden Realities? (forthcoming)

World Bank (2012) Well Begun, Not Yet Done: Vietnam's Remarkable Progress on Poverty Reduction and the Emerging Challenges. 2012 Vietnam Poverty Assessment. Hanoi: World Bank.

This research brief was written in August 2015. The author would like to acknowledge the invaluable support of the Southern Institute of Social Studies in Ho Chi Minh City, Helen Karki Chettri and Kimberly Wied in the process of data collection and analysis. This research was funded by ESRC grant ES-K001833-1.

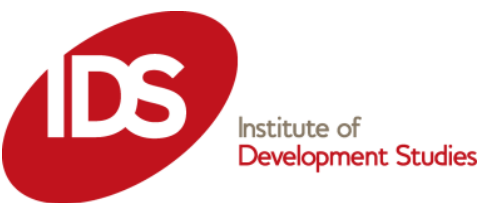

